\title{
Concealed pre-excitation causing paroxysmal reciprocating atrioventricular tachycardia in infancy
}

\author{
K. A. HALLIDIE-SMITH, D. KRIKLER, AND A. MITCHELL \\ Division of Cardiovascular Disease, Royal Postgraduate Medical School, Hammersmith Hospital, London
}

SUMMARY We report 3 infants with Wolff-Parkinson-White (WPW) syndrome who presented with life-threatening paroxysmal reciprocating atrioventricular tachycardia in their first month of life. The diagnosis was confirmed by electrophysiological studies at ages 2-4 years, but the characteristic ECG of pre-excitation has not been shown in one patient and was first recorded at 2 and 3 years in the other two. In 2 patients the tachycardia proved refractory to treatment with digoxin alone but responded to the addition of propranalol or verapamil. One of these infants was converted to sinus rhythm by DC countershock, giving time to reconsider his treatment with drugs. Digoxin is a well-tried treatment acting by slowing AV conduction and interrupting the re-entry circuit. However, it may act more slowly than other agents that act on the AV node-such as intravenous verapamil. Our patients illustrate the value of long follow-up as the diagnosis of WPW syndrome could not be made in infancy. Many infants who present with paroxysmal supraventricular tachycardia in infancy may have an inapparent bypass and be examples of the WPW syndrome.

Paroxysmal tachycardia was recognised in infants by Sir Thomas Lewis in 1915. A series of 9 infants was described in 1941 by Hubbard and by 1963 some 250 cases had been reported (Lundberg, 1963), so that the entity is not rare. A recent report gave an incidence of almost $0.2 \%$ in a series of 1212 consecutive asymptomatic 6 to 9-day-old babies who had an ECG recorded (Southall et al., 1977). Reports however, have been mainly concerned with symptomatic infants and Nadas et al. (1952) among others have emphasised that severe symptoms and fatalities may occur even in infants who have no structural cardiac defect. Thus, prompt recognition and treatment of the tachycardia are essential. Although pre-excitation is recognised as being a major cause of supraventricular tachycardia in infants and children, case reports of infants are comparatively few. Long-term follow-up studies have shown a good prognosis for children and adults (Hubbard, 1941; Nadas et al., 1952; Lundberg, 1963; Giardina et al., 1972) and have confirmed that the serious clinical problem relates to the young infant. In recent years electrophysiological studies in adults, Received 7 February 1978 children, and infants (Goldreyer and Bigger, 1971; Wellens, 1971; Kaye et al., 1975; Gillete, 1976) have greatly increased the understanding of the mechanism of supraventricular tachycardia in all age groups and have stimulated interest in the tachycardias and the natural history of pre-excitation, the diagnosis of which is customarily based on the classical electrocardiographic finding of the Wolff-Parkinson-White (WPW) syndrome. While it is recognised that the ECG may revert to normal (Lundberg, 1963; Bhandhusavee et al., 1972) and its intermittent nature has been noted (Lundberg, 1963; Moene and Roos, 1973) little attention has been paid to the appearance of the diagnostic ECG which may explain the otherwise unexplained cause of some of the paroxysmal tachycardias of infancy on the basis of a concealed accessory atrioventricular connection.

We report 3 infants who presented with lifethreatening supraventricular tachycardia. In one the ECG remained normal; in the other two the ECG appearances of pre-excitation were delayed, yet in all 3 accessory atrioventricular connections were shown by subsequent electrophysiological studies. 


\section{Electrophysiological studies}

The 3 children were studied using electrophysiological methods and measurements previously described (Curry, 1975). Informed parental consent was obtained. The children were studied in the fasting state and sedated with Omnopon. Electrode catheters (USCl. 4F) were placed high in the right atrium, opposite the His bundle, in the right ventricle and the coronary sinus, the latter catheter being used to record and pace from left atrium and left ventricle. Measurements were made of the functional and effective refractory periods of the AV node and other tissues using the extra stimulus test at physiological heart rates. The shortest atrial cycle length that was conducted $1: 1$ across an AV pathway during rapid atrial pacing, and the shortest ventricular cycle length were observed during $1: 1 \mathrm{AV}$ conduction, as well as the sinus node recovery time after the cessation of pacing (Mandel et al., 1971). Conventional intracardiac conduction intervals were accurately measured-namely, the AH interval representing AV node conduction time and the HV interval.

\section{Case studies}

Case 1. A term baby boy, birthweight $3 \cdot 2 \mathrm{~kg}$ who presented at 3 weeks of age with a 2-day history of lassitude, shortness of breath, and loose stools. He was found to be pale, sweaty, tachypnoeic, and in severe congestive cardiac failure with a resting heart rate of over $200 / \mathrm{min}$. ECG showed supraventricular tachycardia at a rate of 320 , at times complicated by transient right bundle-branch block. He was given oral digoxin $(0.04 \mathrm{mg} / \mathrm{kg}$ in 24 hours) and subsequently a daily dose of $0.01 \mathrm{mg} / \mathrm{kg}$ and a single dose of frusemide $1 \mathrm{mg} / \mathrm{kg}$ IM. After 48 hours the ECG reverted to sinus rhythm and the resting ECG was normal. Cardiovascular examination was normal. Several follow-up ECGs remained normal until age 2 years when the WPW syndrome type A was recorded. The child is now 6 years and this pattern has persisted. There have been no recurrences of paroxysmal tachycardia.

He was admitted for electrophysiological study at age $3 \frac{1}{2}$ years. This confirmed the presence of a left-sided accessory atrioventricular connection. The maximum rate of tachycardia was 200 , with anterograde conduction via the AV node, and retrograde conduction along the bypass. Tachycardias were difficult to initiate by premature beats and were short lived, although after IV verapamil they were easily maintained. The child was thus unlikely to have further episodes of tachycardia.
Case 2. A term baby boy, birthweight $3.6 \mathrm{~kg}$, forceps delivery for fetal distress, was noted to have an irregular heart beat at birth. ECG recorded on the 2 nd day of life showed atrial echo beats. He was discharged home on his 8th day but readmitted at age 6 weeks because of feeding difficulties and shortness of breath. His heart rate was noted to be in excess of 200 but an ECG was not recorded because he was thought to have a sinus tachycardia consistent with a pyrexia of $38.5^{\circ}$ due to an Escherichia coli urinary infection. This infection was treated, he became afebrile and was sent home on sulphadimidine but was readmitted a week later afebrile, collapsed, and in severe cardiac failure.

ECG showed supraventricular tachycardia (270 beats/min) with normal intraventricular conduction (Fig. 1) apart from a period of left bundle-branch aberration. He was given IM digoxin $0.02 \mathrm{mg} / \mathrm{kg}$ and IM frusemide $1 \mathrm{mg} / \mathrm{kg}$ but he rapidly deteriorated and had a generalised convulsion; soon afterwards he sustained a cardiac arrest during a lumbar puncture performed to exclude meningitis. He was effectively resuscitated but required assisted ventilation. He was given $15 \mathrm{mg}$ IV phenytoin followed by a maintenance dose of $25 \mathrm{mg}$ t.i.d. and was also started on oral propranalol $2 \mathrm{mg} 8$-hourly. A total dose of digoxin $0.04 \mathrm{mg} / \mathrm{kg}$ was given in 24 hours and then given orally $0.01 \mathrm{mg} / \mathrm{kg}$ each day. He reverted to sinus rhythm 2 hours later. There was no evidence of an infection and he was discharged 2 weeks later no longer in heart failure and with no evidence of an intracardiac defect, on digoxin, propranalol, and phenytoin. He was readmitted again 3 weeks later in mild heart failure in supraventricular tachycardia which reverted spontaneously to sinus rhythm some hours after admission. Thereafter, he has had no further acute problem but now aged 6 years, still gets short self-limiting episodes of tachycardia which no longer disturb him. His mother recognised the attacks in infancy by his pallid appearance and irritability, and in childhood by 'fluttering' in his neck. Digoxin was discontinued

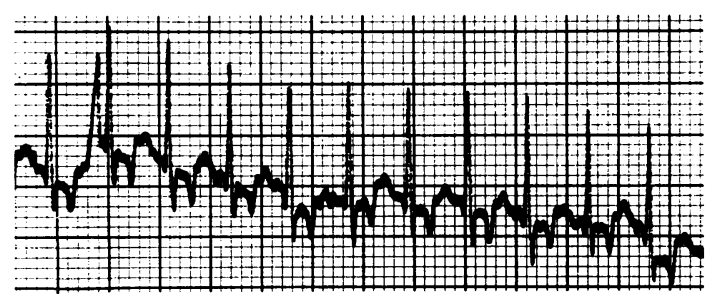

Fig. 1 Case 2. ECG at 7 weeks of age showing paroxysmal atrioventricular tachycardia with normal intraventricular conduction. Ventricular rate 270 beats/min (Lead II); note $P^{\prime}$ after each $Q R S$. 
after one year and propranolol and phenytoin after 6 months. Serial ECGs were normal until age 3 years, when a tracing showed WPW syndrome type B (Fig. 2). Subsequent ECGs have varied, showing either a normal tracing (Fig. 3), intermittent WPW (Fig. 4), or sustained WPW syndrome.

Electrophysiological studies were carried out at age 4 years. These confirmed the presence of a rightsided accessory atrioventricular pathway. The effective refractory period of the accessory tract in the anterograde direction was longer than the interval between sinus beats giving apparent unidirectional block. Tachycardias were relatively easily initiated by premature atrial beats, exhibiting variable left and right bundle-branch block patterns. There was a very wide anterograde re-entry zone which would mean the easy initiation of reciprocating tachycardias during normal life, in exercise, or during a fever. The therapeutic implications of the study suggested that drugs which suppress AV nodal conduction would probably inhibit re-entry tachycardia as well as equalise refractory periods of both anterograde pathways.

Case 3. A term baby boy, birthweight $4 \cdot 1 \mathrm{~kg}$, was discharged home fit at 48 hours but readmitted 2 weeks later because of persistent feeding difficulties. He was found to be in gross congestive cardiac failure with a heart rate of over $200 / \mathrm{min}$. ECG showed regular tachycardia of 250 with left bundle-branch block. IM lanoxin $0.02 \mathrm{mg}$ and IV practolol $0.5 \mathrm{mg}$ had no effect so cardioversion

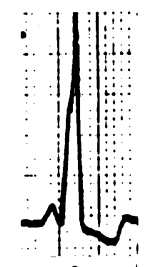

I

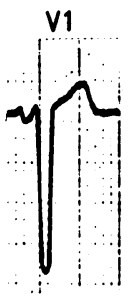

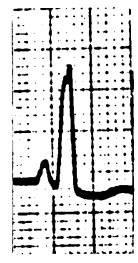

II

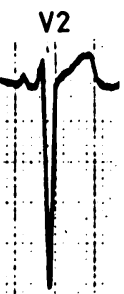

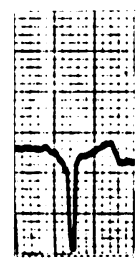

III

V3

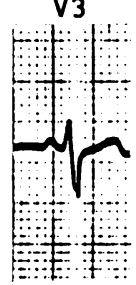

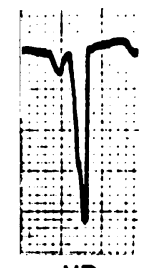

aVR

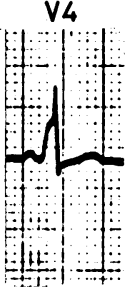

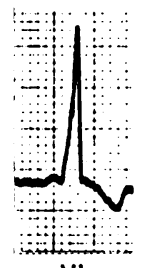

QVL<smiles>[134S]</smiles>

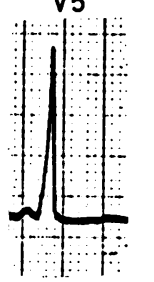

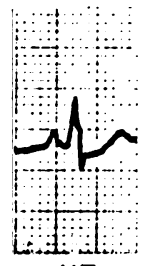

aVF

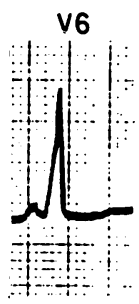

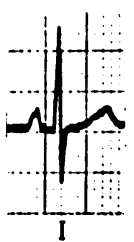
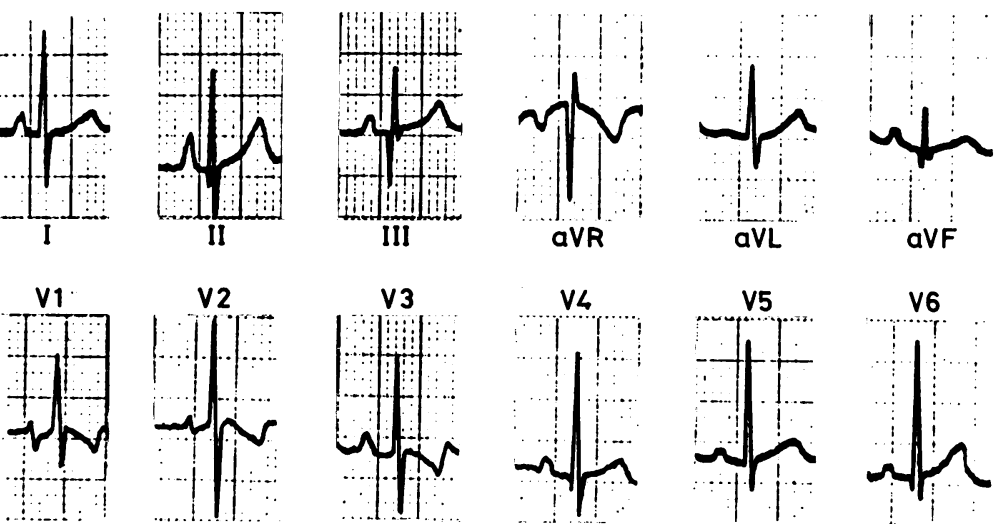
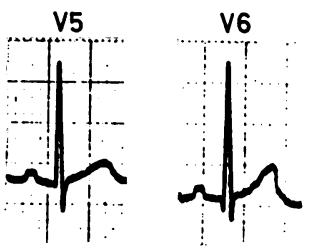

Fig. 2 Case 2. ECG at routine outpatient visit aged 3 years showing $W P W$ syndrome (type B).

Fig. 3 Case 2. ECG at 7 weeks of age, showing no evidence of pre-excitation. 


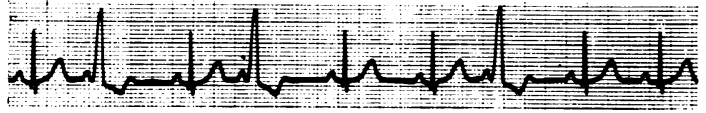

Fig. 4 Case 2. ECG at routine outpatient visit aged 4 years showing intermittent pre-excitation (Lead II).

was attempted and the baby reverted to sinus rhythm with $1 \mathrm{~W} /$ second. Further recurrences of the tachycardia were treated successfully either by DC cardioversion or IV verapamil $(0 \cdot 15 \mathrm{mg} / \mathrm{kg})$. The baby was maintained on lanoxin $0.01 \mathrm{mg} / \mathrm{kg}$ per day and given daily IM frusemide $(4 \mathrm{mg})$ until the heart failure resolved. The cardiac findings were normal as were the resting ECGs and there was no evidence of an infection. The baby was sent home on maintenance digoxin. During the next year he continued to have episodes of tachycardia which needed hospital admission but were all treated successfully with IV verapamil. At one year of age he sustained a right hemiplegia and episodes of tachycardia persisted for a further 4-6 months but ceased to cause symptoms and were self-limiting. $\mathrm{He}$ is now 5 years with normal cardiac findings and a mild residual hemiplegia. All his resting ECGs have been normal but on one tracing there was a single complex showing pre-excitation after termination of a tachycardia with IV verapamil.

Electrophysiological investigations at age 2 years demonstrated a left-sided accessory atrioventricular connection (WPW syndrome type A). There was no anterograde conduction via the anomalous pathways, but retrograde activation demonstrated a refractory period $<200$ milliseconds. Tachycardias were easily maintained only while left bundlebranch block pattern was seen. However, drugs slowing AV nodal conduction allowed tachycardias to be maintained with normal intraventricular conduction. Tachycardias were never prolonged and aborted spontaneously.

\section{Discussion}

Our patients presented as critically ill infants and emphasise the diagnostic and therapeutic urgency of supraventricular tachycardia in this age group. The clinical presentation of low cardiac output, sometimes associated with signs of congestive cardiac failure can equally well be seen in young infants with severe infections who may have a sinus tachycardia in the region of 200. Accurate counting of the heart rate in infants is difficult and it is mandatory to record an ECG in any sick infant with an unmodifiable rapid heart rate. The severity of symptoms in paroxysmal tachycardia in infants relates more closely to duration of the episode than to the rate (Hubbard, 1941) which again emphasises the necessity of having an index of suspicion of the underlying problem. Fortunately one of our patients (Case 2) was resuscitated after cardiac arrest but infant deaths have been reported directly referable to the tachycardia (Werley, 1925; Kimball and Burch, 1947; Silverman and Werner, 1950; Engle, 1952) and it is conceivable that paroxysmal tachycardia may be a cause of sudden death in a seemingly healthy infant (Keeton et al., 1977). Deaths have also been related to treatment (Nadas et al., 1952). Complications of the tachycardias seem rare and we cannot directly relate the hemiplegia of our patient (Case 3) to the tachycardia, but ventricular mural thrombi have been described in a fatal case (Nadas et al., 1952) and it is conceivable that this episode was embolic.

The incidence of pre-excitation in paroxysmal supraventricular tachycardia in infancy is not known but it is generally thought to be $9-13 \%$ in infants and children (Nadas et al., 1952; Keith et al., 1958). Burkiett (1954) reported a 9-13\% incidence in infants but Lundberg (1963) found that 26 of 51 infants showed pre-excitation some time during their first year of life. He explained this high incidence $(57 \%)$ by his having taken multiple ECGs during the first year and noted that $25 \%$ of the infants had a normal ECG after the acute attack. Follow-up of our 3 patients resulted in confirmation of the WPW syndrome in two. Delayed appearance of preexcitation has been noted in adults (Krikler, 1975) and Sung et al. (1977) have drawn attention to concealed WPW syndrome in infants, children, and adults presenting with recurrent supraventricular tachycardia, as reported in our Case 3. These reports lend support to the view that pre-excitation may be the commonest cause of supraventricular tachycardia in infancy (Lundberg, 1963). The appearance of delta-waves depends on the relative properties of the AV nodes and the anomalous pathways, their differing response to drugs and to changes in autonomic tone. The intermittent accessory conduction in Case 2 reflects its long refractory period. The delayed appearance of delta-waves in Cases 1 and 2 is in keeping with physiological slowing of conduction with growth (Scherf and Cohen, 1964) rather than with improvement in anterograde conduction in the accessory pathway. Mandel et al. (1974) demonstrated a greater rate of tachycardia, higher incidence of induced tachycardia, and shorter SA and AV node and bypass refractory periods in children compared with adults.

Digitalis has often been used in the treatment of paroxysmal tachycardia in infancy; Giardina et al. (1972) successfully treated 28 of 29 patients. However, 2 of our 3 patients were refractory to digitalis 
alone and unsuccessful treatment has been reported (Schiebler et al., 1959; Swiderski et al., 1962). Verapamil also acts on the AV node and appears to be a highly effective drug, given IV, for treatment of reciprocating tachycardia with or without bypass (Krikler and Spurrell, 1974). However, this drug, like the $\beta$-blockers, is primarily an AV node blocker and, as demonstrated in our first patient, may occasionally introduce a critical degree of delay in the AV node so that re-entry can occur using a bypass. Thus if the tachycardia cannot be successfully treated by an AV nodal blocking drug (digitalis, verapamil, or $\beta$-blocker) an agent which preferentially blocks the accessory pathway (ventricular myocardium)-such as procainamide-should be used.

The sick infant with paroxysmal tachycardia needs urgent treatment. Vagal stimulation is ineffective in this age group (Swiderski et al., 1962; Lundberg, 1963). DC countershock which was successful in Case 3 may allow time to consider an effective drug regimen. Verapamil was successful in this particular infant, and is an appropriate immediate therapy (Krikler and Spurrell, 1974) given in a rapid IV injection, but it must not be given if the infant has already received a $\beta$-blocker because of the combined negative inotropic action (Nayler and Krikler, 1974). The converse is equally true and $\beta$-blockers are less effective than verapamil and their use is not advocated. The indications for long-term drug prophylaxis have not been established. Two of our patients (Cases 1 and 2) were maintained on treatment for 12 and 6 months respectively but, in retrospect, this was not justified in Case 1. As persistent and symptomatic tachycardias are unusual after the first 6-12 months of life (Giardina et al., 1972) there seems, in general, little indication for continuing prophylactic treatment beyond infancy.

We thank Dr P. Curry for carrying out the electrophysiological studies and Dr D Stone for referring Case 3.

\section{References}

Bhandhusavee, R. V., Walters, L. R., and Noonan, I. A. (1972). Wolff-Parkinson-White syndrome in the neonate; nine cases, including two with internal defects (abstract). American Journal of Cardiology, 29, 253.

Burkiett, V. R. D. (1954). La Tachycardia paroxystique du nourisson. Thèse. Faculté de Médecine de Paris.

Curry, P. V. L. (1975). In Cardiac Arrhythmias: the Modern Electrophysiological Approach, chapter 3, p. 39. Edited by D. M. Krikler and J. F. Goodwin. Saunders: London.
Engle, M. A. (1952). Wolff-Parkinson-White syndrome in infants and children. American Journal of Diseases of Children, 82, 692-705.

Giardina, A. C. V., Ehlers, K. H., and Engle, M. A. (1972). Wolff-Parkinson-White syndrome in infants and children. A long-term follow-up study. British Heart Journal, 34, 839-846.

Gillete, P. C. (1976). The mechanisms of supraventricular tachycardia in children. Circulation, 54, 133-139.

Goldreyer, B. N., and Bigger, J. T., Jr (1971). Site of reentry in paroxysmal supraventricular tachycardia in man. Circulation, 43, 15-26.

Hubbard, J. P. (1941). Paroxysmal tachycardia and its treatment in young infants. American Journal of Diseases of Children, 61, 687-709.

Kaye, H. H., Reid, D. S., and Tynan, M. (1975). Studies in a newborn infant with supraventricular tachycardia and Wolff-Parkinson-White syndrome. British Heart Journal, 37, 332-335.

Keeton, B. N., Southall, B., Nutter, N., Anderson, R. H., Shinebourne, E. A., and Southall, D. P. (1977). Cardiac conduction disorders in six infants with 'near miss' sudden infant deaths. British Medical Journal, 2, 600-601.

Keith, J. D., Rowe, R., and Vlad, D. (1958). Heart Disease in Infancy and Childhood. Macmillan: New York.

Kimball, J. L., and Burch, G. (1947). The prognosis of the Wolff-Parkinson-White syndrome. Annals of Internal Medicine, 27, 239-242.

Krikler, D. M. (1975). In Cardiac Arrhythmias: the Modern Electrophysiological Approach, chapter 6, p. 144. Edited by D. M. Krikler and J. F. Goodwin. Saunders: London.

Krikler, D. M., and Spurrell, A. J. (1974). Verapamil in the treatment of paroxysmal supraventricular tachycardia. Postgraduate Medical Journal, 50, 447-453.

Lewis, T. (1915). Lectures on the Heart. Hoeber: New York.

Lundberg, A. (1963). Paroxysmal tachycardia in infancy. A clinical and experimental study. Acta paediatrica, 52, 192-195.

Mandel, W. J., Hayakawa, H., Danzig, R., and Marcus, H. S. (1971). Evaluation of sinoatrial node function in man by overdrive suppression. Circulation, 44, 59-66.

Mandel, W. J., Laks, M. M., Fink, B., and Oyabashi, K. (1974). Comparative electrophysiologic features of the WPW syndrome in the paediatric and adult patient (abstract). American Journal of Cardiology, 33, 153.

Moene, R. J., and Roos, J. P. (1973). Transient WolffParkinson-White syndrome and neonatal reciprocating tachycardia. Circulation, 48, 443-447.

Nadas, A. S., Daeschner, C. W., Roth, A., and Blumenthal, S. L. (1952). Paroxysmal tachycardia in infants and children. Pediatrics, 9, 167-181.

Nayler, W. G., and Krikler, D. M. (1974). Verapamil and the myocardium. Postgraduate Medical Journal, 50, 441-446.

Scherf, D., and Cohen, J. (1964). The Atrioventricular Node and Selected Cardiac Arrhythmias, chapter 15, p. 374. Grune and Stratton: New York.

Schiebler, G. L., Adams, P., Jr, and Anderson, R. C. (1959). Wolff-Parkinson-White syndrome in infants and children. Pediatrics, 24, 585-603.

Silverman, J. J., and Werner, M. (1950). Fatal paroxysmal tachycardia in a newborn infant with the Wolff-ParkinsonWhite syndrome. Journal of Pediatrics, 37, 765-773. 
Southall, D. P., Orrell, M. J., Talbot, J. F., Brinton, R. J., Vulliamy, D. F., Johnson, A. M., Keeton, B. R., Anderson, R. M., and Shinebourne, E. A. (1977). Study of cardiac arrhythmias and other forms of conduction abnormality in newborn infants. British Medical Journal, 2, 597-599.

Sung, R. J., Gelband, H., Castellanos, A., Aranda, J., and Myerburg, R. J. (1977). Clinical and electrophysiologic observations in patients with concealed accessory atrioventricular bypass tracts. American Journal of Cardiology, 40, 839-847.

Swiderski, J., Lees, M. H., and Nadas, A. S. (1962). WolffParkinson-White syndrome in infancy and childhood. British Heart Journal, 24, 561-580.
Wellens, H. J. J. (1971). Electrical Stimulation of the Heart in the Study and Treatment of Tachycardias, p. 119. Stenfert Kroese: Leiden.

Werley, G. (1925). Paroxysmal tachycardia with ventricular rate of three hundred and seven in a child four days old. Archives of Pediatrics, 42, 825-826.

Correspondence to Dr K. A. Hallidie-Smith, Royal Postgraduate Medical School, Hammersmith Hospital, London W12 0HS.

The following articles will appear in future issues of this journal:

Solute and calorie loading in young infants: short- and long-term effects. L. S. Taitz.

The incomplete male. M. O. Savage and D. B. Grant.

Pyridoxol metabolism in vitamin B6-responsive convulsions of early infancy. A. Heeley, R. J. P. Pugh, B. E. Clayton, J. Shepherd, and J. Wilson.

Stress response and its relationship to cystic (pseudofollicular) change in the definitive cortex of the adrenal gland in stillborn infants. D. J. deSa.

Nonstructural heart disease in the newborn: observations during one year in a perinatal service. $R$. D. Rowe, T. Izukawa, H. C. Mulholland, K. R. Bloom, D. H. Cook, and P. R. Swyer.

Cockayne's syndrome and emphysema. M. Cunningham, S. Godfrey, and W. M. V. Moffat.

Significance of raised immunoglobulin $M$ levels in cord blood of small-for-gestational-age infants. T. Matthews and C. O'Herlihy.

Reappraisal of linoleic acid requirement of the young infant, with particular regard to use of modified cows milk formulae. D. J. Naismith, S. P. Deeprose, G. Supramaniam, and M. J. H. Williams. 